\title{
A novel morphometric signature of brain alterations in type 2 diabetes: patterns of changed cortical gyrification
}

Joana Crisóstomo ${ }^{1,2}$, João V. Duarte ${ }^{1,2}$, Carolina Moreno ${ }^{1,3}$, Leonor Gomes ${ }^{1,3}$, Miguel CasteloBranco $^{1,2}$ (corresponding author: mcbranco@fmed.uc.pt)

${ }^{1}$ University of Coimbra, Coimbra Institute for Biomedical Imaging and Translational Research (CIBIT), Institute for Nuclear Sciences Applied to Health (ICNAS), Portugal

${ }^{2}$ University of Coimbra, Faculty of Medicine (FMUC), Portugal

${ }^{3}$ Department of Endocrinology, Centro Hospitalar e Universitário de Coimbra (CHUC), Portugal

\section{Abstract}

Type 2 diabetes is a chronic disease that creates atrophic signatures in the brain, including decreases of total and regional volume of grey matter, white matter, and cortical thickness. However, there is a lack of studies assessing cortical gyrification in type 2 diabetes. Changes in this emerging feature has been associated mainly with genetic legacy, but environmental factors may also play a role. Here, we investigated alterations of the gyrification index and classical morphometric measures in type 2 diabetes, a disease with complex etiology with both underlying genetic and more preponderant environmental factors.

In this cross-sectional study we analyzed brain anatomical magnetic resonance images of 86 participants with type 2 diabetes and 40 healthy control participants, to investigate structural alterations in type 2 diabetes, including whole-brain volumetric measures, local alterations of grey matter volume, cortical thickness and the gyrification index.

We found concordant significant decrements in total and regional grey matter volume, and cortical thickness. Surprisingly, the cortical gyrification index was found to be mainly increased in cortical sensory areas in type 2 diabetes. Moreover, it correlated with features of metabolic control. Our findings challenge the classical neurodevelopmental association of gyrification mostly with genetic determinants. While we found mainly increased gyrification in more genetically constrained sensory areas in type 2 diabetes, our correlation results concurrently suggest an influence of metabolic control in alterations of gyrification in type 2 diabetes. Further studies should address causal influences of genetic and/or environmental factors in patterns of cortical gyrification in type 2 diabetes.

Keywords: Brain; Morphometry; Gyrification; Sensory cortex; Type 2 diabetes 
medRxiv preprint doi: https://doi.org/10.1101/2021.02.25.21252196; this version posted February 26, 2021. The copyright holder for this preprint (which was not certified by peer review) is the author/funder, who has granted medRxiv a license to display the preprint in perpetuity. All rights reserved. No reuse allowed without permission.

\section{Introduction}

Type 2 diabetes is a highly prevalent chronic metabolic disease that affects many tissues and organs, and the brain is not an exception. Despite the ongoing controversies on the nature of its impact in the brain, changes in structure and function are well documented in diabetes. This disease is commonly associated with cerebrovascular disease, cognitive decline, Alzheimer's disease and other types of dementias and depression [Bancks et al., 2017; Cheng et al., 2012; Moheet et al., 2015; Verdile et al., 2015]. Studies of structural magnetic resonance imaging (MRI) with volumetric analysis at the whole-brain level and voxel-based morphometry (VBM) have shown brain atrophy, including lower total and regional volume of grey matter (GM) and white mater (WM) in type 2 diabetes patients when compared to non-diabetic controls [Moheet et al., 2015; Moran et al., 2013]. Decrements in cortical thickness were also already demonstrated with surface-based morphometry (SBM) studies in type 2 diabetes patients [Chen et al., 2017; Moran et al., 2019]. Conceptually, the volume of GM and the cortical thickness seem to be influenced by environmental factors related with diabetes progression, such as patients' glycemic profile, lipidic status, vascular complications and insulin taking [Brundel et al., 2010; Bryan et al., 2014; Chen et al., 2015; Chen et al., 2017; Shi et al., 2019]. Notably, cortical gyrification is an interesting surface feature that has been suggested to be more specifically determined by genetic and neurodevelopmental factors [Ronan and Fletcher, 2015], which to the best of our knowledge was never assessed in type 2 diabetes.

Gyrification refers to the development of the folding surface patterns on the brain [Welker, 1990; Zilles et al., 1988], being highly heritable, evolutionarily conserved, and similar amongst closely related animal species [Alexander-Bloch et al., 2020; Zilles et al., 2013]. Due to gyrification, the cortical surface area and thus the volume of cortical GM can increase dramatically [White et al., 2010]. It is postulated to be dictated by the genetic signature and the period of greatest development of brain gyrification is during intrauterine development [Papini et al., 2020; White et al., 2010]. Genetic control of this process is now starting to be understood both in animal models using genome editing [Johnson et al., 2018] and also in the human brain [Alexander-Bloch et al., 2020]. A quantitative approach to measure local gyrification is known as the gyrification index, which is a ratio between the length of the outer folded surface of the brain, including sulci, and the length of the outer surface excluding sulci [Schaer et al., 2008; Yotter et al., 2011; Zilles et al., 1988]. The development of this quantification concept has allowed to identify altered gyrification in several diseases with genetic or neurodevelopmental basis as well as in complex etiology diseases [Bearden et al., 2009; Casanova et al., 2004; Gaser et al., 2006; Jou et al., 2010; Lebed et al., 2013; Lin et al., 
2007; Palaniyappan and Liddle, 2012; Zhang et al., 2010]. Besides alterations in pathologically impaired brains, there is also evidence suggesting that changes in gyrification also occur due to environmental factors [Amunts et al., 1997; Luders et al., 2012], as well as in healthy ageing [Hogstrom et al., 2013; Lamballais et al., 2020]. However, there is no investigation regarding this cortical feature in diabetes.

We hypothesize that it is conceivable that alterations in the brain surface morphology, namely in gyrification, may also occur in diabetes, thus following the trend of documented structural changes and functional impairments in this complex disease.

In this cross-sectional study we aimed at investigating this novel feature of cortical gyrification in type 2 diabetes, as well as more classical structural measures, including whole-brain volumetric tissue volumes - total intracranial volume (TIV), GM, WM, and cerebrospinal fluid (CSF), local GM volume and cortical thickness.

\section{Materials and Methods}

\subsection{Participants}

After signing the informed consent, 190 participants were enrolled in a cross-sectional study, between 2012-2014, and divided in two experimental groups: a type 2 diabetes group (T2D) and a control group (CNT). Type 2 diabetes patients were recruited at the Endocrinology Department of the University of Coimbra Hospital, diagnosed using standard WHO criteria at the moment of recruitment, based on glucose levels, oral glucose tolerance test and glycated hemoglobin (HbA1c) [WHO, 1999; WHO, 2011]. Inclusion criteria for type 2 diabetes group were: (i) age between 40 and 75 years; and (ii) type 2 diabetes for at least 1 year before the enrolment in the study. Control individuals were recruited from the general population of the hospital or university staff and their relatives. Inclusion criteria for CNT group were: (i) age between 40 and 75 years and (ii) type 2 diabetes diagnosis excluded based on levels of $\mathrm{HbA} 1 \mathrm{c}$ and fasting glucose. General exclusion criteria were: (i) history of neurological or psychiatric disorders; (ii) substance abuse/dependence; and (iii) contra-indication for MR imaging.

Demographic and clinical data were collected for all participants by research physicians and fasting blood samples were collected by venous puncture by research nurses for posterior biochemical analysis, according to the hospital standard procedures. 
The study was approved by the Ethics Commission of the Faculty of Medicine of the University of Coimbra and was conducted in accordance with the declaration of Helsinki. All participants provided written informed consent to participate in the study.

\subsection{Magnetic resonance imaging data acquisition}

Data were collected at the Institute of Nuclear Sciences Applied to Health - University of Coimbra, using a Siemens Magnetom TIM Trio 3 Tesla MRI scanner with a phased array 12-channel birdcage head coil (Siemens, Munich, Germany). For each participant, 3D anatomical T1-weighted MPRAGE (magnetization-prepared rapid gradient echo) images were acquired with the following parameters: repetition time $(T R)=2530$ milliseconds; echo time $(T E)=3.42$ milliseconds; inversion time $(T I)=$ 1100 milliseconds; flip angle $7^{\circ} ; 176$ single-shot interleaved slices with no gap with isotropic voxel size $1 \times 1 \times 1 \mathrm{~mm}$; field of view $(\mathrm{FOV})=256 \mathrm{~mm}$.

\subsection{Data analysis}

Out of 190 participants recruited, 17 dropped out before MRI scanning. Additionally, 3 participants were excluded after a quality assessment by visual inspection of acquired structural data, because of severe movement artefacts and anatomical anomalies. Then, aiming to do between-groups analysis balanced for age, 86 type 2 diabetes participants and 40 CNT participants were selected, which is well above recommended sizes for neuroimaging studies [Friston, 2012]. Images were processed and analyzed using SPM12 (Wellcome Trust Centre for Neuroimaging, London, UK; http://www.fil.ion.ucl.ac.uk/spm/software/spm12/) and CAT12 toolbox (Structural Brain Mapping Group, Jena University Hospital, Jena, Germany; http://dbm.neuro.unijena.de/cat/), as it offers processing and analysis pipelines for both voxel-based morphometry (VBM) as well as surface-based morphometry (SBM) (including cortical thickness and gyrification index). This toolbox has been previously used and validated in morphometric studies in clinical populations, including by our own group [Madeira et al., 2020].

\subsubsection{Voxel-based morphometry}

After quality assessment of original images, the images were centered in the anterior commissure and oriented in AC-PC (anterior commissure - posterior commissure) plane. Subsequently, images were spatially normalized into Montreal Neurological Institute (MNI) standard space and segmented into three tissue classes - grey matter (GM), white matter (WM) and cerebrospinal fluid (CSF) - using 
medRxiv preprint doi: https://doi.org/10.1101/2021.02.25.21252196; this version posted February 26, 2021. The copyright holder for this preprint

(which was not certified by peer review) is the author/funder, who has granted medRxiv a license to display the preprint in perpetuity.

All rights reserved. No reuse allowed without permission.

partial volume segmentation with adaptive maximum a posteriori approach. Total intracranial volume (TIV) was also determined for all scans. The extracted modulated normalized GM maps were smoothed using a $12 \mathrm{~mm}$ full width at half maximum (FWHM) kernel and used for further analysis. An absolute masking threshold of 0.1 was applied to the VBM data. The Automated Anatomical Labelling and Yale Biolmage Suite (v1.3) brain atlases were used to label the regions with differences between groups, according to their MNI coordinates.

\subsubsection{Cortical thickness}

Cortical thickness was extracted based on the absolute mean curvature approach [Luders et al., 2006]. Extraction of the cortical surface (using CAT12 standard procedure) resulted in the construction of a mesh of the central surface, i.e., the surface between the GM/CSF border and the GM/WM boundary. The central surface as well as cortical thickness are estimated in one step using a projection-based distance measure [Dahnke et al., 2013]. The vertex-wise cortical thickness measures were resampled and smoothed using a 15 mm FWHM gaussian kernel.

\subsubsection{Gyrification index}

Local (vertex-wise) gyrification index maps were calculated based on the same algorithm for extraction of the cortical surface implemented in CAT12, as given above for cortical thickness analysis [Luders et al., 2006; Yotter et al., 2011]. The local absolute mean curvature of this central surface was then calculated by averaging the mean curvature values from each vertex point within $3 \mathrm{~mm}$ from a given point. In a second step, we applied $15 \mathrm{~mm}$ FWHM smoothing to the gyrification index maps.

\subsection{Statistical analysis}

The analysis of demographic, clinical data, and total brain volumes (TIV, GM, WM, CSF) was performed with GraphPad Prism 6. Normality of the data was tested using D'Agostino-Pearson test. Parametric and non-parametric tests were used when data were normally distributed or when assumption of normality was not met, respectively. Parametric t-test and non-parametric MannWhitney test were used to assess between-groups differences. Parametric Pearson test and nonparametric Spearman test were used to calculate correlations between disease-related parameters (glucose, $\mathrm{HbA1c}$, age at diagnosis and disease duration) and the gyrification index. Chi-square test was used to assess the difference in gender distribution between groups.

The statistical analyses of imaging data were performed in the CAT12/SPM12 statistical module applying t-test to each of the three morphometric measures: GM volume with VBM, and cortical 
thickness and gyrification index with SBM. Using age and gender as covariates (and for VBM analyses, additionally, TIV), group differences applying thresholds of $p<0.05$ with family-wise error rate (FWE) correction for multiple comparisons were tested. When the correction was too stringent, and not to miss an exploratory interesting effect, the statistical maps were thresholded at voxel level with $p<0.001$ and then corrected at the cluster level with cluster extent correction.

\section{Results}

\subsection{Demographic and clinical data}

Demographic and clinical data are depicted in Table 1. The mean age of type 2 diabetes group was 60.67 years and of CNT was 57.73 years and no statistically significant difference between groups was found. Gender distribution between groups was also not different. As expected, type 2 diabetes group showed significantly higher levels of fasting glucose and $\mathrm{HbA1C}$, when compared with controls. The mean age at diagnosis of diabetes was 47.73 years and mean disease duration was 12 years. All patients were taking oral antidiabetic drugs, $81.3 \%$ of which in combination with insulin (data not shown).

Table 1: Demographic and clinical data

\begin{tabular}{lccccc}
\hline & & T2D & CNT & Test & $p$ value \\
Number & & 86 & 40 & & \\
\hline Age (years) & & $60.67 \pm 7.89$ & $57.73 \pm 8.06$ & $t=1.94$ & 0.06 \\
Gender (\%) & Male & 59.3 & 50 & $X^{2}=0.96$ & 0.33 \\
& Female & 40.7 & 50 & & \\
Fasting glucose $(\mathrm{mg} / \mathrm{dL})$ & $166.5 \pm 62.56$ & $95.05 \pm 10.89$ & $U=295.5$ & $<0.0001$ \\
& $(\mathrm{mmol} / \mathrm{mol})$ & $79.53 \pm 25.72$ & $35.13 \pm 3.98$ & $t=10.21$ & $<0.0001$ \\
Glycated Hemoglobin & $(\%)$ & $9.43 \pm 2.37$ & $5.36 \pm 0.38$ & & - \\
& & $47.73 \pm 10.26$ & - & - & - \\
Age at diagnosis (years) & $12.05 \pm 8.88$ & - & - & \\
Disease duration (years) & &
\end{tabular}

Data are presented as mean \pm SD for continuous data or \% for categorical data.

\subsection{Volumetric analysis}

Volumetric measures for the included participants are Figure 1. type 2 diabetes group had significantly lower TIV ( $p<0.05)$, and total GM and WM volume $(p<0.0001$, for both) in comparison 
to the control group. In contrast, the total CSF volume was significantly higher $(p<0.05)$ in participants with type 2 diabetes than in control participants.

\section{- Figure 1 -}

\subsection{Voxel-based morphometry analysis}

VBM analysis of GM showed 18 clusters with significantly decreased GM volume in participants with type 2 diabetes (Figure 2), whereas 5 clusters were located in frontal lobe (D, E, G, L and N), 3 clusters in limbic lobe ( $B, C$ and $R$ ), 2 clusters in occipital lobe ( $K$ and $M), 2$ clusters in posterior lobe ( $F$ and H), 1 cluster in temporal lobe (Q), and 5 clusters were found in sub-lobar regions of insula (A, I, J and P) and of lentiform nucleus (O).

\section{- Figure 2 -}

\subsection{Cortical thickness analysis}

SBM analysis of cortical thickness revealed 3 clusters with significantly decreased cortical thickness in participants with type 2 diabetes (Figure 3). Clusters were found in temporal lobe (A and $C$ ) and in the limbic lobe (B).

\section{- Figure 3 -}

\subsection{Cortical gyrification analysis}

SBM analysis of cortical gyrification index showed a distinctive pattern in particular in sensory regions, revealing 5 clusters with a significant increase in cortical gyrification index in participants with type 2 diabetes and only 1 with lower gyrification index in type 2 diabetes patients (Figure 3). Clusters with increased gyrification index were found in temporal lobes ( $C$ and $F$ ), posterior lobe (B), parietal lobe (D) and occipital lobe (E). The cluster with decreased gyrification index was in the temporal lobe $(A)$.

\section{- Figure 4 -}

The relation between the local gyrification index and clinical data, presented in Table 2, was significant only in clusters with increased gyrification in type 2 diabetes patients. A moderate negative correlation between disease duration and left occipital cortex (cluster F) was found. We also observed positive weak correlations with fasting glucose in left visual cortex (cluster E) and with $\mathrm{HbA1C}$ in right fusiform gyrus and left occipital cortex (cluster B and F, respectively). 
Table 2: Correlations between gyrification index and clinical data

\begin{tabular}{llcccccc}
\hline Clusters & & $\mathbf{A}^{*}$ & $\mathbf{B}^{\#}$ & $\mathbf{C}^{\#}$ & $\mathbf{D}^{\#}$ & $\mathbf{E}^{\#}$ & $\mathbf{F}^{\#}$ \\
\hline \multirow{2}{*}{ Fasting glucose $(\mathbf{n = 8 3})$} & Spearman rho & $-0,198$ & 0,12 & 0 & $-0,028$ & 0,219 & $-0,013$ \\
& $p$ & 0,07 & 0,275 & 0,999 & 0,799 & 0,044 & 0,908 \\
\multirow{2}{*}{ Glycated hemoglobin } & Pearson $\boldsymbol{r}$ & $-0,06$ & 0,232 & 0,051 & 0,059 & 0,103 & 0,266 \\
& $p$ & 0,588 & 0,035 & 0,647 & 0,596 & 0,355 & 0,015 \\
Age at diagnosis & Pearson $r$ & $-0,027$ & 0,095 & 0,189 & 0,138 & $-0,042$ & 0,012 \\
& $p$ & 0,837 & 0,476 & 0,153 & 0,297 & 0,749 & 0,931 \\
Disease duration & Spearman rho & 0,066 & $-0,094$ & 0,015 & 0,052 & 0,195 & $-0,38$ \\
& $p$ & 0,617 & 0,479 & 0,91 & 0,698 & 0,139 & 0,003 \\
\hline
\end{tabular}

${ }^{*} \mathrm{~T} 2 \mathrm{D}<\mathrm{CNT} ;{ }^{*} \mathrm{~T} 2 \mathrm{D}>\mathrm{CNT}$

\section{Discussion}

Diabetes is known to impair brain structure and function. Cerebrovascular complications, alterations in glucose homeostasis and insulin signaling, are the factors present in diabetes that most likely affect brain integrity and this is even more critical as neural tissue is highly dependent on glucose to function.

Here we targeted morphometric properties which are not captured by VBM or cortical thickness analyses, by evaluating for the first time cortical gyrification in type 2 diabetes. This feature has been postulated to be more determined by genetic factors mainly during the fetal development [Papini et al., 2020; White et al., 2010; Zilles et al., 1988; Zilles et al., 2013]. Accordingly, the literature has consistently reported altered gyrification index in diseases with genetic or neurodevelopmental basis [Bearden et al., 2009; Gaser et al., 2006; Jou et al., 2010; Palaniyappan and Liddle, 2012]. Nonetheless, the brain nearly triples its size from birth to adulthood and alterations in brain morphology, including in gyrification index, also occur in healthy aging [Hogstrom et al., 2013; Lamballais et al., 2020]. Changes have also been observed in late acquired and diseases with more complex etiology [Lebed et al., 2013; Lin et al., 2007]. These observations raise credit to the notion that changes in gyrification index may occur due to environmental factors [Amunts et al., 1997; Luders et al., 2012].

Regarding the complex etiology of type 2 diabetes, with underlying both genetic and more preponderant environmental factors, we hypothesized that alterations in the brain surface morphology, namely in gyrification, may also occur, in addition to the expected structural changes 
medRxiv preprint doi: https://doi.org/10.1101/2021.02.25.21252196; this version posted February 26, 2021. The copyright holder for this preprint (which was not certified by peer review) is the author/funder, who has granted medRxiv a license to display the preprint in perpetuity. All rights reserved. No reuse allowed without permission.

and functional impairments. To the best of our knowledge, there are no studies assessing the cortical gyrification index in type 2 diabetes in humans.

In this study, we were able to find changes in gyrification index, mainly observed in primary sensory areas. A recent study showing higher correlations between local genetic patterns and cortical folding in somatosensory areas, which suggests evidence that the topology of primary cortex is more constrained by genetics influence than association higher-older cortical areas [Alexander-Bloch et al., 2020]. The fact that the sensory cortex has thicker layers, namely layer IV that receives most projections from the thalamus, might underlie the higher proneness of sensory areas to suffer alterations of gyrification. Ronan et al. have indeed postulated that thalamocortical connectivity is critical to gyrification patterns [Ronan and Fletcher, 2015]. Furthermore, the increase of cortical surface area in sensory regions, as a mechanism to decrease metabolic costs associated with higher degree of local connectivity, might confer additional predisposition to alterations of gyrification in these areas [Alexander-Bloch et al., 2020]. Thus, we believe our finding might be attributed, in part, to a genetic impact, but possibly also to acquired damage to the thalamus, a vulnerable region, and its connections. Importantly, different characteristics of gyrification, such as length and shape of sulci and gyri, might be affected differently by distinct factors. There is evidence of a moderate degree of genetic control over variation in sulcal length, while gyrus-shape features are more susceptible to environmental effects [Atkinson et al., 2015]. This fact further supports the notion that although gyrification is suggested to be more genetically controlled, other factors, namely environmental, might play a role in alterations of gyrification. A study with an animal model of diabetes supports the idea of environmental influence in gyrification. This study showed a severe reduction in cortical convolution in streptozotocin-induced diabetic rats, that showed improvements in this morphologic measure after an antioxidant treatment [Nurdiana et al., 2018]. Therefore, these results leave open the possibility that also the metabolic control might have an effect in gyrification. Notably, in our analysis, we observed significant correlations of the gyrification index with measures reflecting metabolic control. A positive correlation of $\mathrm{HbA} 1 \mathrm{c}$ and fasting glucose with increased gyrification in type 2 diabetes suggests a role of hyperglycemia in increasing gyrification index in type 2 diabetes. On the other hand, we observed a negative correlation of disease duration with increased gyrification index in type 2 diabetes. This finding suggests that longer disease duration somehow diminishes the difference of gyrification index in type 2 diabetes relative to healthy controls, which seems to be a summation effect of disease with that of age in gyrification. 
In contrast to our results showing decrease in GM volume and thickness, we mainly observed increased gyrification in type 2 diabetes compared to healthy controls. The fact that type 2 diabetes brains showed a higher gyrification index was surprising for us, as we expected it would follow the tendency of other morphometric measures. This suggests a more complex underlying mechanism possibly involved. The diabetic brain is susceptible to a pathological environment including inflammation, oxidative stress, and hypoxia, leads ultimately to axonal damage and cellular death. Brain atrophy is related with neurological insult but gyrification may also be affected by other factors such as connectivity changes [Ronan and Fletcher, 2015]. Interestingly, previous studies showed the same pattern of cortical morphology change, a thinning of the cortex accompanied by an increase in gyrification, in diseases with more genetic or neurodevelopmental basis, such as 22q11.2 deletion [Bearden et al., 2009], Williams syndrome [Gaser et al., 2006], autism [Jou et al., 2010], and schizophrenia [Palaniyappan and Liddle, 2012].

Using more conventional measures we could also show that diabetes impacts brain structure, although literature is not fully consistent, in particular when samples sizes are small. Notably, we could observe highly significant differences in the total volumes of brain tissues, namely the global reduction of GM and WM in type 2 diabetes patients, which is in line with a study with a large cohort of type 2 diabetes patients [Moran et al., 2013] . This reduction was accompanied by a difference also in TIV, which may not be higher due to the increase in CSF values in the type 2 diabetes group. Less studied, increases in CSF volume are related with aging and with dementia [Tanna et al., 1991; White et al., 2010]. Therefore, this increase in our type 2 diabetes population is not surprising. VBM analysis also supported what we found at the whole-brain level, showing only clusters with lower GM volume in type 2 diabetes group. Consistently, we only observed regional cortical thinning in type 2 diabetes group. These results are in accordance with previous studies of brain atrophy using VBM [Moran et al., 2013; Moulton et al., 2015; Wang et al., 2014] and cortical thickness [Brundel et al., 2010; Chen et al., 2015; Chen et al., 2017; Li et al., 2018; Shi et al., 2019] analysis in diabetic populations. In our study, decreased regional GM volumes appeared in several regions in type 2 diabetes patients, mainly in the frontal lobe, as in [Moran et al., 2013; Moulton et al., 2015; Roy et al., 2020], and sub-lobar cortex. Specifically, we observed decreased GM volume in different clusters of the insula, which has been implicated in an overwhelming variety of functions ranging from sensory processing to representation of feelings and emotions [Roy et al., 2020]. This structure was already reported to present impaired neurovascular coupling in an fMRI study with the same cohort [Duarte et al., 2015]. As previously highlighted [Moran et al., 2013; Roy et al., 2020], lower regional 
GM volume in type 2 diabetes was also observed in our study in the limbic lobe, namely in the cingulate cortex and bilateral parahippocampal gyrus. Furthermore, there was a concomitant GM volume reduction and cortical thinning of the parahippocampal gyrus. A region in the temporal lobe also showed a decrease in cortical thickness [Chen et al., 2017; Li et al., 2018].

\section{Conclusion}

Summing up, we found a novel signature of changed brain structure in type 2 diabetes, the gyrification index, in addition to the expected whole-brain cortical atrophy. Our results regarding the gyrification index are surprising and cannot be simply explained by local neural loss mechanisms. Notably, we found mainly increased gyrification in sensory areas in type 2 diabetes. While a genetic influence should be considered, our correlation results concurrently suggest an influence of metabolic control in alterations of gyrification in type 2 diabetes. Sensory areas are dominated by strong thalamocortical input, and axonal damage might contribute to gyrification changes. This is an important issue to consider in further studies of gyrification in diabetes, addressing the complex etiology of the disease and assessing different underlying factors, including both genetic and environmental determinants. Furthermore, a longitudinal approach will be crucial to investigate in more detail the mechanisms underlying these alterations, ultimately as a potential new biomarker in diabetes management.

\section{Acknowledgments}

We thank the participants for their involvement in this study. We also thank C. Ferreira and J. Marques from ICNAS, University of Coimbra, for help with MRI procedures.

\section{Author contributions}

JC, JVD, CM, LG and MCB contributed to conception and design of the study. JVD performed acquisition of data. JC and JVD performed data analysis and interpretation. JC, JVD and MCB wrote the paper. JC, JVD, CM, LG and MCB contributed to the discussion and revised the manuscript.

\section{Data availability statement:}

The datasets generated during and/or analysed during the current study are available from the corresponding author on reasonable request. 


\section{Funding statement:}

This work was supported by Fundação para a Ciência e Tecnologia (UID/4959/2020, DSAIPA/DS/0041/2020, DolT - Diamarker: a consortium for the discovery of novel biomarkers in diabetes - QREN-COMPETE), INFARMED Research Fund for Health (FIS-FIS-2015-01 DIA DiaMarkData), and the European Foundation for the Study of Diabetes (EFSD) 2019 - Innovative Measurement of Diabetes Outcomes 2019. Fundação para a Ciência e Tecnologia also funded an individual grant to JVD (Individual Scientific Employment Stimulus 2017 - CEECIND/00581/2017).

\section{Conflict of interest disclosure:}

The authors declare no conflict of interest.

\section{Ethics approval statement:}

The study was approved by the Comissão de Ética da Faculdade de Medicina da Universidade de Coimbra and was conducted in accordance with the declaration of Helsinki. All participants provided written informed consent to participate in the study.

\section{References}

Alexander-Bloch AF, Raznahan A, Vandekar SN, Seidlitz J, Lu Z, Matthias SR, Knowles E, Mollon J, Rodrigue A, Curran JE, Görring HHH, Satterthwaite TD, Gur RE, Bassett DS, Hoftman GD, Pearlson G, Shinohara RT, Liu S, Fox PT, Almasyr L, Blangero J, Glahn DC (2020): Imaging local genetic influences on cortical folding. Proc Natl Acad Sci U S A 117:7430-7436.

Amunts K, Schlaug G, Jäncke L, Steinmetz H, Schleicher A, Dabringhaus A, Zilles K (1997): Motor cortex and hand motor skills: Structural compliance in the human brain. Hum Brain Mapp $5: 206-215$.

Atkinson EG, Rogers J, Mahaney MC, Cox LA, Cheverud JM (2015): Cortical folding of the primate brain: An interdisciplinary examination of the genetic architecture, modularity, and evolvability of a significant neurological trait in pedigreed baboons (genus papio). Genetics 200:651-665.

Bancks MP, Alonso A, Gottesman RF, Mosley TH, Selvin E, Pankow JS (2017): Brain function and structure and risk for incident diabetes: The Atherosclerosis Risk in Communities Study. Alzheimer's Dement 13:1345-1354. http://dx.doi.org/10.1016/j.jalz.2017.04.006.

Bearden CE, Van Erp TGM, Dutton RA, Lee AD, Simon TJ, Cannon TD, Emanuel BS, McDonald-Mcginn 
D, Zackai EH, Thompson PM (2009): Alterations in midline cortical thickness and gyrification patterns mapped in children with 22q11.2 deletions. Cereb Cortex 19:115-126.

Brundel M, Van Den Heuvel M, De Bresser J, Kappelle LJ, Biessels GJ (2010): Cerebral cortical thickness in patients with type 2 diabetes. J Neurol Sci 299:126-130. http://dx.doi.org/10.1016/j.jns.2010.08.048.

Bryan RN, Bilello M, Davatzikos C, Lazar RM, Murray A, Horowitz K, Lovato J, Miller ME, Williamson J, Launer $\amalg$ (2014): Effect of diabetes on brain structure: The action to control cardiovascular risk in diabetes MR imaging baseline data. Radiology 272:210-216.

Casanova MF, Araque J, Giedd J, Rumsey JM (2004): Reduced brain size and gyrification in the brains of dyslexic patients. J Child Neurol 19:275-281.

Chen Z, Sun J, Yang Y, Lou X, Wang Y, Wang Y, Ma L (2015): Cortical thinning in type 2 diabetes mellitus and recovering effects of insulin therapy. J Clin Neurosci 22:275-279. http://dx.doi.org/10.1016/j.jocn.2014.07.014.

Chen Z, Zang X, Liu M, Liu M, Li J, Gu Z, Ma L (2017): Abnormal Alterations of Cortical Thickness in 16 Patients with Type 2 Diabetes Mellitus: A Pilot MRI Study. Chinese Med Sci J 32:75-82. http://dx.doi.org/10.24920/J1001-9294.2017.010.

Cheng G, Huang C, Deng H, Wang H (2012): Diabetes as a risk factor for dementia and mild cognitive impairment: A meta-analysis of longitudinal studies. Intern Med J 42:484-491.

Dahnke R, Yotter RA, Gaser C (2013): Cortical thickness and central surface estimation. Neuroimage 65:336-348.

Duarte J V., Pereira JMS, Quendera B, Raimundo M, Moreno C, Gomes L, Carrilho F, Castelo-Branco M (2015): Early disrupted neurovascular coupling and changed event level hemodynamic response function in type 2 diabetes: An fMRI study. J Cereb Blood Flow Metab 35:1671-1680. Friston K (2012): Ten ironic rules for non-statistical reviewers. Neuroimage 61:1300-1310.

Gaser C, Luders E, Thompson PM, Lee AD, Dutton RA, Geaga JA, Hayashi KM, Bellugi U, Galaburda AM, Korenberg JR, Mills DL, Toga AW, Reiss AL (2006): Increased local gyrification mapped in Williams syndrome. Neuroimage 33:46-54.

Hogstrom L, Westlye LT, Walhovd KB, Fjell AM (2013): The structure of the cerebral cortex across adult life: Age-related patterns of surface area, thickness, and gyrification. Cereb Cortex 23:2521-2530.

Johnson MB, Sun X, Kodani A, Borges-Monroy R, Girskis KM, Ryu SC, Wang PP, Patel K, Gonzalez DM, Woo YM, Yan Z, Liang B, Smith RS, Chatterjee M, Coman D, Papademetris X, Staib LH, Hyder F, 
Mandeville JB, Grant PE, Im K, Kwak H, Engelhardt JF, Walsh CA, Bae B-I (2018): Aspm knockout ferret reveals an evolutionary mechanism governing cerebral cortical size. Nature 556:370375. https://www.ledsmagazine.com/articles/print/volume-15/issue-5/features/developerforum/reconsider-uv-c-led-lifetime-for-disinfection-based-on-developmentdecisions.html\%0Ahttp://dx.doi.org/10.1371/journal.pone.0202275\%0Ahttp://stacks.iop.org /1882-0786/10/.

Jou RJ, Minshew NJ, Keshavan MS, Hardan AY (2010): Cortical Gyrification in Autistic and Asperger Disorders: A Preliminary Magnetic Resonance Imaging Study. J Child Neurol 25:1462-1467. http://journals.sagepub.com/doi/10.1177/0883073810368311.

Lamballais S, Vinke EJ, Vernooij MW, Ikram MA, Muetzel RL (2020): Cortical gyrification in relation to age and cognition in older adults. Neuroimage 212:116637. https://doi.org/10.1016/j.neuroimage.2020.116637.

Lebed E, Jacova C, Wang L, Beg MF (2013): Novel Surface-Smoothing Based Local Gyrification Index. IEEE Trans Med Imaging 32:660-669. http://ieeexplore.ieee.org/document/6365821/.

Li C, Li C, Yang Q, Wang B, Yin X, Zuo Z, Hu X, Lai Y, Wang J (2018): Cortical thickness contributes to cognitive heterogeneity in patients with type 2 diabetes mellitus. Med (United States) 97:1-7.

Lin JJ, Salamon N, Lee AD, Dutton RA, Geaga JA, Hayashi KM, Luders E, Toga AW, Engel J, Thompson PM (2007): Reduced neocortical thickness and complexity mapped in mesial temporal lobe epilepsy with hippocampal sclerosis. Cereb Cortex 17:2007-2018.

Luders E, Thompson PM, Narr KL, Toga AW, Jancke L, Gaser C (2006): A curvature-based approach to estimate local gyrification on the cortical surface. Neuroimage 29:1224-1230.

Luders E, Kurth F, Mayer EA, Toga AW, Narr KL, Gaser C (2012): The Unique Brain Anatomy of Meditation Practitioners: Alterations in Cortical Gyrification. Front Hum Neurosci 6:1-9.

Madeira N, Duarte JV, Martins R, Costa GN, Macedo A, Castelo-Branco M (2020): Morphometry and gyrification in bipolar disorder and schizophrenia: A comparative MRI study. Neurolmage Clin 26.

Moheet A, Mangia S, Seaquist ER (2015): Impact of diabetes on cognitive function and brain structure. Ann N Y Acad Sci 1353:60-71. http://doi.wiley.com/10.1111/nyas.12807.

Moran C, Beare R, Wang W, Callisaya ML, Srikanth V (2019): Type 2 diabetes mellitus, brain atrophy, and cognitive decline. Neurology 92:e1-e8.

Moran C, Phan TG, Chen J, Blizzard L, Beare R, Venn A, Münch G, Wood AG, Forbes J, Greenaway TM, Pearson S, Srikanth V (2013): Brain atrophy in type 2 diabetes: Regional distribution and 
influence on cognition. Diabetes Care 36:4036-4042.

Moulton CD, Costafreda SG, Horton P, Ismail K, Fu CHY (2015): Meta-analyses of structural regional cerebral effects in type 1 and type 2 diabetes. Brain Imaging Behav 9:651-662.

Nurdiana S, Goh YM, Hafandi A, Dom SM, Nur Syimal'ain A, Noor Syaffinaz NM, Ebrahimi M (2018): Improvement of spatial learning and memory, cortical gyrification patterns and brain oxidative stress markers in diabetic rats treated with Ficus deltoidea leaf extract and vitexin. J Tradit Complement Med 8:190-202.

Palaniyappan L, Liddle PF (2012): Aberrant cortical gyrification in schizophrenia: A surface-based morphometry study. J Psychiatry Neurosci 37:399-406.

Papini C, Palaniyappan L, Kroll J, Froudist-Walsh S, Murray RM, Nosarti C (2020): Altered Cortical Gyrification in Adults Who Were Born Very Preterm and Its Associations With Cognition and Mental Health. Biol Psychiatry Cogn Neurosci Neuroimaging 5:640-650. https://doi.org/10.1016/j.bpsc.2020.01.006.

Ronan L, Fletcher PC (2015): From genes to folds: a review of cortical gyrification theory. Brain Struct Funct 220:2475-2483. http://dx.doi.org/10.1007/s00429-014-0961-z.

Roy B, Ehlert L, Mullur R, Freeby MJ, Woo MA, Kumar R, Choi S (2020): Regional Brain Gray Matter Changes in Patients with Type 2 Diabetes Mellitus. Sci Rep 10:1-13. http://dx.doi.org/10.1038/s41598-020-67022-5.

Schaer M, Bach Cuadra M, Tamarit L, Lazeyras F, Eliez S, Thiran JP (2008): A Surface-based approach to quantify local cortical gyrification. IEEE Trans Med Imaging 27:161-170.

Shi L, Cheng Y, Xu Y, Shen Z, Lu Y, Zhou C, Jiang L, Zhang Y, Zhu F, Xu X (2019): Effects of hypertension on cerebral cortical thickness alterations in patients with type 2 diabetes. Diabetes Research and Clinical Practice.

Tanna NK, Kohn MI, Horwich DN, Jolles PR, Zimmerman RA, Alves WM, Alavi A (1991): Analysis of brain and cerebrospinal fluid volumes with MR imaging: impact on PET data correction for atrophy. Part II. Aging and Alzheimer dementia. Radiology 178:123-130. http://pubs.rsna.org/doi/10.1148/radiology.178.1.1984290.

Verdile G, Fuller SJ, Martins RN (2015): The role of type 2 diabetes in neurodegeneration. Neurobiol Dis 84:22-38. http://dx.doi.org/10.1016/j.nbd.2015.04.008.

Wang CX, Fu KL, Liu HJ, Xing F, Zhang SY (2014): Brain structural changes and their correlation with vascular disease in type 2 diabetes mellitus patients: A voxel-based morphometric study. Neural Regen Res 9:1548-1556. 
Welker W (1990): Why Does Cerebral Cortex Fissure and Fold? In: pp 3-136.

White T, Su S, Schmidt M, Kao C-Y, Sapiro G (2010): The development of gyrification in childhood and adolescence. Brain Cogn 72:36-45. https://www.ncbi.nlm.nih.gov/pmc/articles/PMC3624763/pdf/nihms412728.pdf.

Yotter RA, Nenadic I, Ziegler G, Thompson PM, Gaser C (2011): Local cortical surface complexity maps from spherical harmonic reconstructions. Neuroimage 56:961-973. http://dx.doi.org/10.1016/j.neuroimage.2011.02.007.

Zhang Y, Zhou Y, Yu C, Lin L, Li C, Jiang T (2010): Reduced cortical folding in mental retardation. Am J Neuroradiol 31:1063-1067.

Zilles K, Armstrong E, Schleicher A, Kretschmann H (1988): Anatomy and Embryology The human pattern of gyrification in the cerebral cortex. Anat Embryol 179:173-179.

Zilles K, Palomero-Gallagher N, Amunts K (2013): Development of cortical folding during evolution and ontogeny. Trends Neurosci 36:275-284. http://dx.doi.org/10.1016/j.tins.2013.01.006. 
medRxiv preprint doi: https://doi.org/10.1101/2021.02.25.21252196; this version posted February 26, 2021. The copyright holder for this preprint (which was not certified by peer review) is the author/funder, who has granted medRxiv a license to display the preprint in perpetuity.

All rights reserved. No reuse allowed without permission.

\section{Figures}

Fig. 1

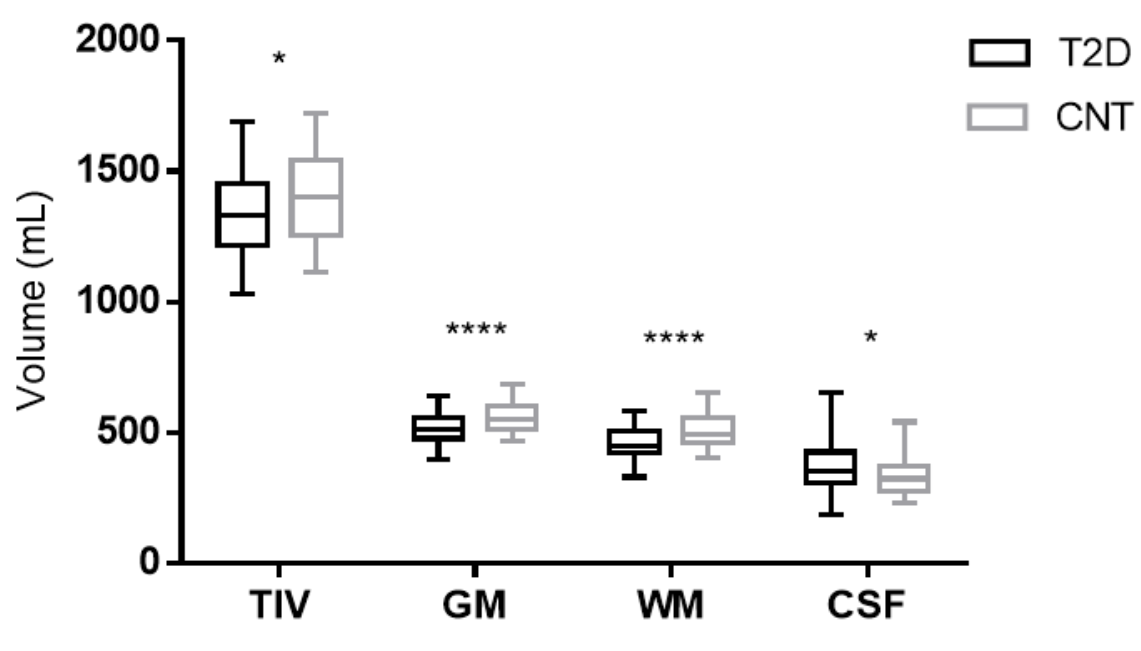


medRxiv preprint doi: https://doi.org/10.1101/2021.02.25.21252196; this version posted February 26, 2021. The copyright holder for this preprint (which was not certified by peer review) is the author/funder, who has granted medRxiv a license to display the preprint in perpetuity.

All rights reserved. No reuse allowed without permission.

Fig. 2 A)

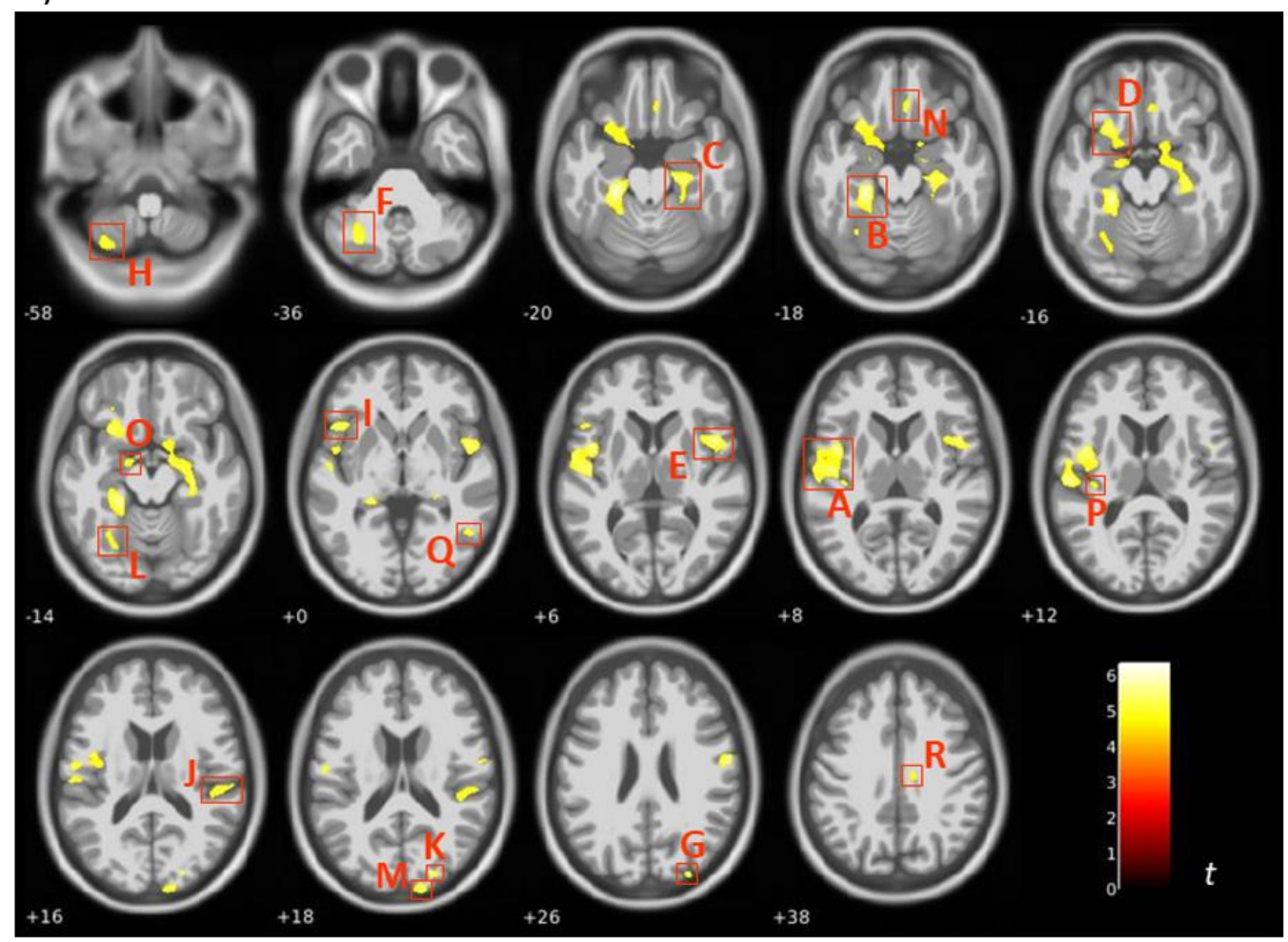

B)

\begin{tabular}{|c|c|c|c|c|c|c|}
\hline \multirow{2}{*}{\multicolumn{2}{|c|}{$\begin{array}{c}\text { Number } \\
\text { voxels/cluster }\end{array}$}} & \multirow{2}{*}{\multicolumn{3}{|c|}{$\begin{array}{c}\text { MNI coordinates } \\
(x, y, z-m m)\end{array}$}} & \multicolumn{2}{|c|}{ Brain region } \\
\hline & & & & & \multirow{2}{*}{$\begin{array}{l}\text { Automated Anatomical Labelling } \\
\text { Left-Insula }\end{array}$} & \multirow{2}{*}{$\begin{array}{l}\text { Yale Biolmage Suite } \\
\text { Left-Insula (BA13) }\end{array}$} \\
\hline A & 4820 & -44 & 2 & 8 & & \\
\hline B & 3920 & -24 & -30 & -18 & Left-Parahippocampal gyrus & $\begin{array}{l}\text { Left-Parahippocampal gyrus } \\
\text { (BA36) }\end{array}$ \\
\hline C & 3789 & 24 & -22 & -20 & Right-Parahippocampal gyrus & $\begin{array}{l}\text { Right-Parahippocampal gyrus } \\
\text { (BA36) }\end{array}$ \\
\hline D & 1900 & -26 & 18 & -16 & Left-Insula & Left-Insula (BA13) \\
\hline $\mathrm{E}$ & 1650 & 46 & 8 & 6 & Right-Insula & Right-BA44 \\
\hline $\mathrm{F}$ & 1433 & -30 & -62 & -36 & Left-Cerebellum & \\
\hline G & 857 & 56 & -6 & 26 & Right-Postcentral gyrus & Right-Primary motor (BA4) \\
\hline H & 672 & -32 & -68 & -58 & Left-Cerebellum & \\
\hline I & 591 & -46 & 18 & 0 & & Left-BA45 \\
\hline $\mathrm{J}$ & 422 & 48 & -26 & 16 & Right-Superior temporal gyrus & Right-BA40 \\
\hline K & 351 & 22 & -86 & 18 & Right-Superior occipital gyrus & Right-BA19 \\
\hline L & 264 & -30 & -60 & -14 & Left-Fusiform gyrus & Left-Fusiform gyrus (BA37) \\
\hline M & 260 & 14 & -96 & 18 & Right-Superior occipital gyrus & Right-Visual associative (BA18) \\
\hline $\mathrm{N}$ & 168 & 6 & 32 & -18 & Right-Gyrus rectus & Right-BA11 \\
\hline $\mathrm{O}$ & 165 & -16 & -8 & -14 & Left-Hippocampus & \\
\hline$P$ & 163 & -36 & -24 & 12 & Left-Heschl gyrus & Left-Primary auditory (BA41) \\
\hline Q & 134 & 48 & -56 & 0 & Right-Middle temporal & Right-Fusiform (BA37) \\
\hline $\mathrm{R}$ & 131 & 12 & -16 & 38 & & Right-BA24 \\
\hline
\end{tabular}


medRxiv preprint doi: https://doi.org/10.1101/2021.02.25.21252196; this version posted February 26, 2021. The copyright holder for this preprint (which was not certified by peer review) is the author/funder, who has granted medRxiv a license to display the preprint in perpetuity.

All rights reserved. No reuse allowed without permission.

Fig. 3

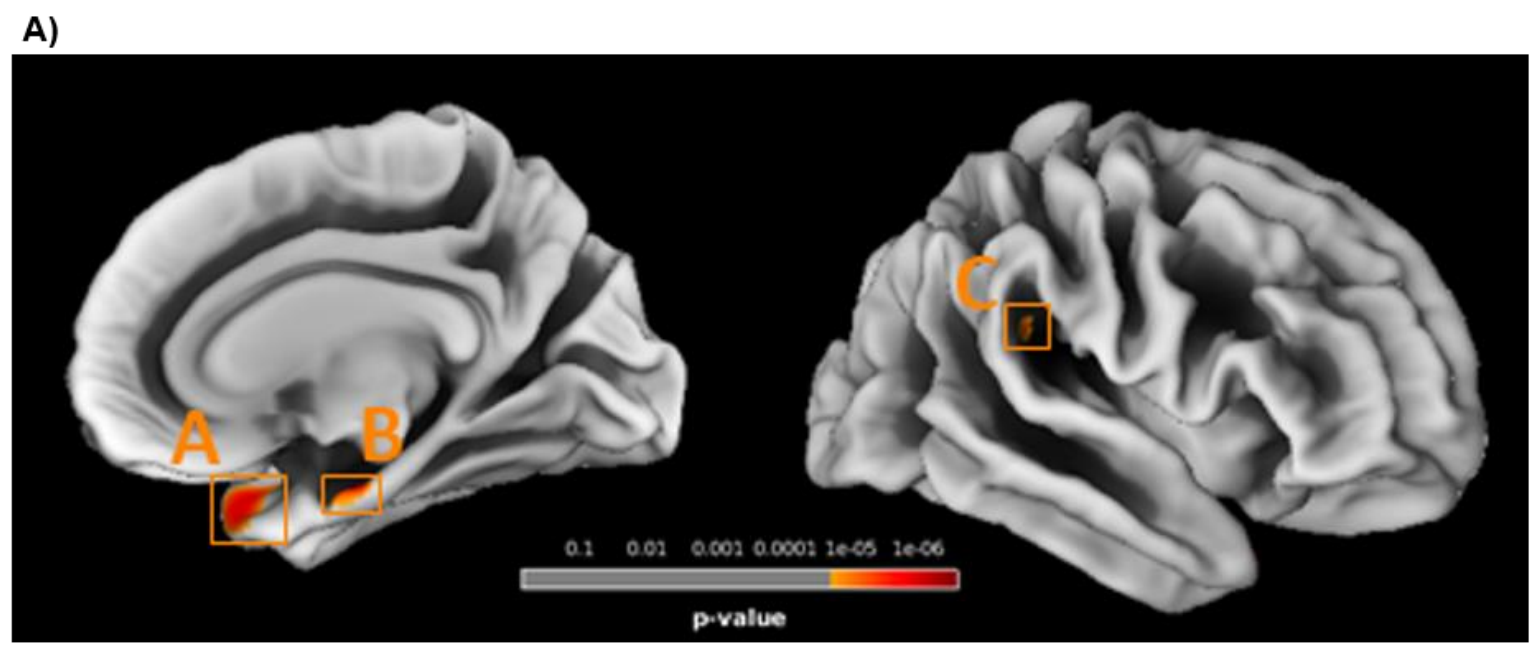

B)

\begin{tabular}{|c|c|c|c|c|c|c|}
\hline & \multirow{2}{*}{$\begin{array}{c}\text { Number } \\
\text { voxels/cluster }\end{array}$} & \multirow{2}{*}{\multicolumn{3}{|c|}{$\begin{array}{c}\text { MNI } \\
\text { coordinates } \\
(\mathrm{x}, \mathrm{y}, \mathrm{z}-\mathrm{mm}) \\
\end{array}$}} & \multicolumn{2}{|c|}{ Brain region } \\
\hline & & & & & Automated Anatomical Labelling & Yale Biolmage Suite \\
\hline A & 73 & 39 & 15 & -28 & Right-Superior temporal pole & Right-BA38 \\
\hline B & 47 & 24 & -15 & -24 & Right-Parahippocampal gyrus & $\begin{array}{l}\text { Right-Parahippocampal gyrus } \\
\text { (BA36) }\end{array}$ \\
\hline $\mathrm{C}$ & 25 & 48 & -37 & 23 & Right-Superior temporal gyrus & Right-BA40 \\
\hline
\end{tabular}


medRxiv preprint doi: https://doi.org/10.1101/2021.02.25.21252196; this version posted February 26, 2021. The copyright holder for this preprint (which was not certified by peer review) is the author/funder, who has granted medRxiv a license to display the preprint in perpetuity.

All rights reserved. No reuse allowed without permission.

Fig. 4

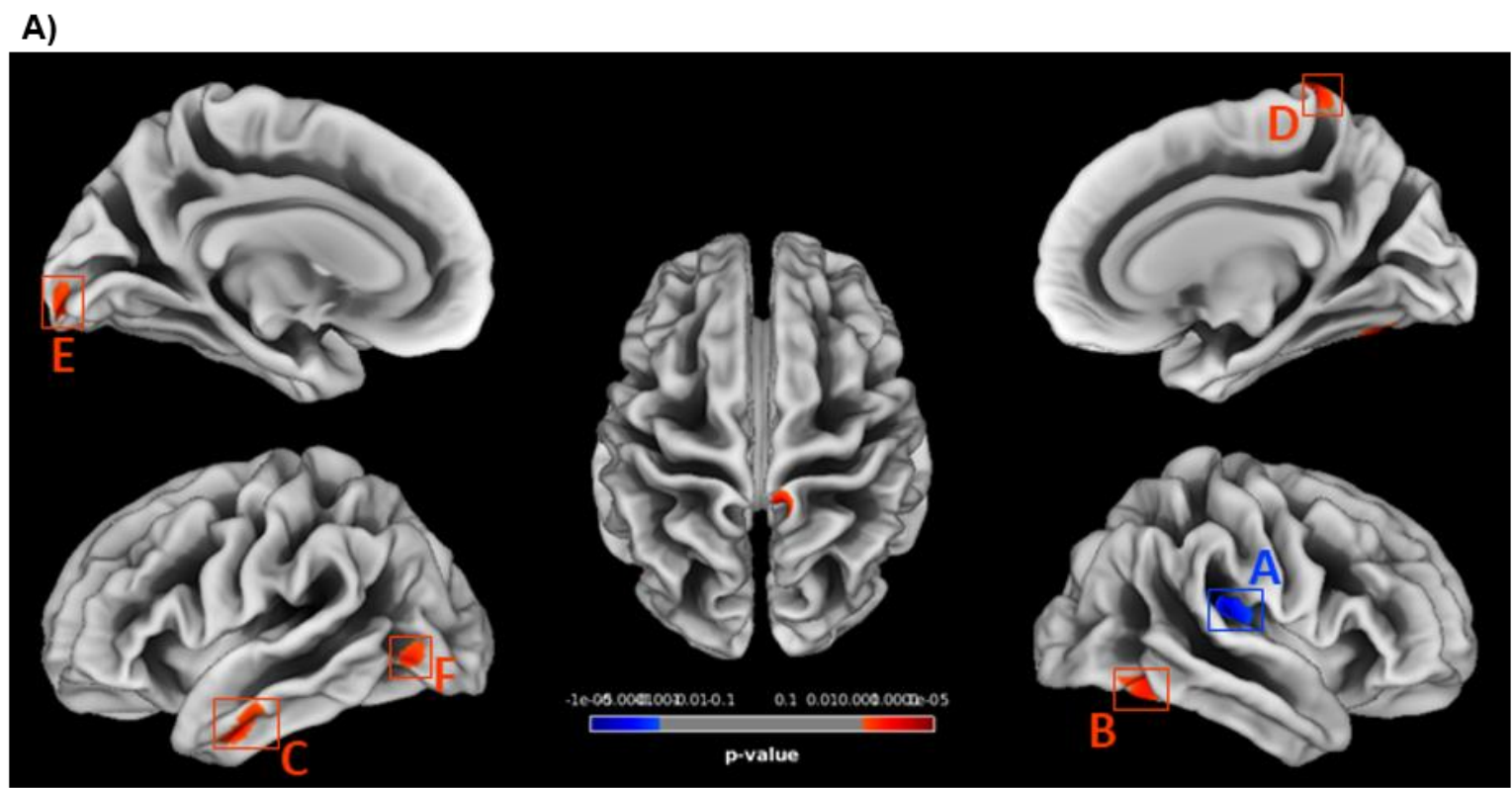

B)

\begin{tabular}{|c|c|c|c|c|c|c|}
\hline & \multirow{2}{*}{$\begin{array}{c}\text { Number } \\
\text { voxels/cluster }\end{array}$} & \multirow{2}{*}{\multicolumn{3}{|c|}{$\begin{array}{c}\text { MNI } \\
\text { coordinates } \\
(\mathrm{x}, \mathrm{y}, \mathrm{z}-\mathrm{mm})\end{array}$}} & \multicolumn{2}{|c|}{ Brain region } \\
\hline & & & & & Automated Anatomical Labelling & Yale Biolmage Suite \\
\hline$A^{*}$ & 188 & 34 & -27 & 11 & & $\begin{array}{l}\text { Right-Primary auditory } \\
\text { (BA41) }\end{array}$ \\
\hline $\mathrm{B}^{\#}$ & 127 & 37 & -63 & -18 & Right-Fusiform gyrus & Right-Fusiform gyrus (BA37) \\
\hline $\mathrm{C}^{\#}$ & 82 & -50 & -6 & -32 & Left-Inferior temporal gyrus & Left-BA20 \\
\hline$D^{\#}$ & 80 & 9 & -40 & 76 & Right-Paracentral lobule & Right-Primary sensory (BA1) \\
\hline$E^{\#}$ & 60 & -9 & -96 & -10 & Left-Calcarine & $\begin{array}{l}\text { Left-Visual associative } \\
\text { (BA18) }\end{array}$ \\
\hline$F^{\#}$ & 57 & -44 & -71 & -4 & Left-Inferior occipital gyrus & Left-BA19 \\
\hline
\end{tabular}




\section{Figure legends}

Figure 1: Boxplots of the distribution of total intracranial volume (TIV), total grey matter (GM), white matter (WM) and cerebrospinal fluid (CSF) volumes in each group. A significant difference between groups is indicated by $* \mathrm{p}<0.05$ and $* * * * p<0.0001$, assessed with $\mathrm{t}$ (TIV, GM and WM) and MannWhitney (CSF) tests.

Figure 2: VBM analysis of GM. (A) Statistical map presenting the clusters with significantly decreased GM volume in type 2 diabetes participants, thresholded at $p<0.05$ with FWE correction for multiple comparisons at voxel level, and with minimum extent cluster size correction ( $K=114)$ at cluster level. (B) Labelling of the regions containing clusters with differences, according to their MNI coordinates, based in the Automated Anatomical Labelling and Yale Biolmage Suite brain atlases.

Figure 3: SBM analysis of cortical thickness. (A) Statistical map presenting the clusters with significantly decreased cortical thickness in type 2 diabetes participants, thresholded at $\mathrm{p}<0.05$ with FWE correction for multiple comparisons at vertex level, and with minimum extent cluster size correction ( $\mathrm{K}=25)$ at cluster level. (B) Labelling of the regions containing clusters with differences, according to their MNI coordinates, based in the Automated Anatomical Labelling and Yale Biolmage Suite brain atlases.

Figure 4: SBM analysis of cortical gyrification. (A) Statistical map presenting the clusters with significantly decreased $(*)$ or increased (\#) cortical gyrification index in type 2 diabetes participants, thresholded at $p<0.001$ at vertex level, and with minimum extent cluster size correction $(K=47)$ at cluster level. (B) Labelling of the regions containing clusters with differences, according to their MNI coordinates, based in the Automated Anatomical Labelling and Yale Biolmage Suite brain atlases. 